\title{
Space-selective valence state manipulation of transition metal ions inside glasses by a femtosecond laser
}

\section{AUTHOR(S):}

Qiu, JR; Zhu, CS; Nakaya, T; Si, JH; Kojima, K; Ogura, F; Hirao, K

\section{CITATION:}

Qiu, JR ... [et al]. Space-selective valence state manipulation of transition metal ions inside glasses by a femtosecond laser. APPLIED PHYSICS LETTERS 2001, 79(22): 3567-3569

\section{ISSUE DATE:}

2001-11-26

URL:

http://hdl.handle.net/2433/39646

\section{RIGHT:}

Copyright 2001 American Institute of Physics. This article may be downloaded for personal use only. Any other use requires prior permission of the author and the American Institute of Physics. 


\title{
Space-selective valence state manipulation of transition metal ions inside glasses by a femtosecond laser
}

\author{
Jianrong $\mathrm{Qiu}^{\mathrm{a})}$ and Congshan Zhu \\ Photon Craft Project, Shanghai Institute of Optics and Fine Mechanics, Chinese Academy of Sciences, \\ Shanghai, China, and Japan Science and Technology Corporation, Keihanna-Plaza, Kyoto 619-0237, Japan \\ Takayuki Nakaya and Jinhai Si \\ Photon Craft Project, Japan Science and Technology Corporation, Keihanna-Plaza, Kyoto 619-0237, Japan \\ Kazuo Kojima and Fumito Ogura \\ Faculty of Science and Engineering, Ritsumeikan University, Kusatsu, Shiga 525-8577, Japan \\ Kazuyuki Hirao \\ Graduate School of Engineering, Kyoto University, Kyoto 606-8501, Japan
}

(Received 26 July 2001; accepted for publication 24 September 2001)

We report the observation of space-selective oxidation of $\mathrm{Mn}^{2+}$ to $\mathrm{Mn}^{3+}$ in a transparent and colorless $\mathrm{Mn}$ and $\mathrm{Fe}$ ions codoped silicate glass at room temperature by using an 800-nm-femtosecond laser. Difference absorption spectrum of the glass after and before the irradiation of the focused infrared femtosecond pulsed laser showed that a portion of $\mathrm{Mn}^{2+}$ ions near the focused part of the laser beam inside the glass were oxidized to $\mathrm{Mn}^{3+}$ ions after the laser irradiation. $\mathrm{Mn}^{3+}$ ions were stable at the temperatures below $300^{\circ} \mathrm{C}$. It is suggested that $\mathrm{Mn}^{2+}$ ions act as hole trapping centers while $\mathrm{Fe}^{3+}$ ions as well as active sites in the glass matrix act as electron trapping centers. A promising application was demonstrated for the fabrication of three-dimensional colored image inside a transparent material. (C) 2001 American Institute of Physics.

[DOI: 10.1063/1.1421640]

Materials with three dimensionally modulated microstructures has potential applications in optical field. ${ }^{1,2} \mathrm{Up}$ to now, there have been much investigation on the threedimensional microfabrication. ${ }^{3-5}$ Braun and Witzius have successfully fabricated three-dimensional structures of semiconductors by template-directed electrochemical deposition. ${ }^{3}$ Cumpston et al. have succeeded in the fabrication of microoptical elements with two-photon photopolymerization. ${ }^{4}$ Holographic lithography has been used to fabricate threedimensional photonic crystals, which have periodical dielectric structures and can manipulate light in much the same way that a superconductor manipulates electrons. ${ }^{5}$

It is well known that laser light can be pulsed and focused to a spot of wavelength order. Ultrashort pulsed laser has been used as a powerful tool to clarify elementary processes, such as excitation-energy relaxation and both electron and proton transfer on nanosecond and picosecond time scales, that occur in a micrometer-sized area. ${ }^{6,7}$ Ultrashort pulsed laser can also be used to make microscopic modifications to transparent materials. The reason for using this laser is that its electric field intensity can reach $100 \mathrm{TW} / \mathrm{cm}^{2}$, which is sufficient for inducing nonlinear optical effects in materials by use of a focusing lens, when the pulse width is $100 \mathrm{fs}$ and the pulse energy is $1 \mu \mathrm{J}$. The photoinduced reaction is expected to occur only near the focused part of the laser beam due to nonlinear optical processes.

Up to now, there have been a lot of studies on the microscopic modifications in transparent materials by using

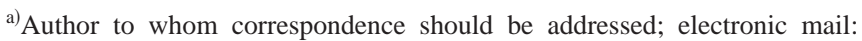
jrq@photon.jst.go.jp
}

femtosecond lasers. ${ }^{8-14}$ Various induced structures can be produced by using pulsed laser operating at the nonresonant wavelength with pulse widths of the order of femtosecond; colored lines due to the formation of color center, refractive index spot due to densification and defect formation, microvoid due to remelting and shock wave, microcrack due to destructive breakdown, etc. ${ }^{14}$ Composite structures were also observed after the focused femtosecond laser irradiation. ${ }^{14}$ Promising applications using these phenomena have also been demonstrated for three-dimensional optical memory, integrated optical circuit, and optical display. ${ }^{8-14}$

In this letter, we report the observation of space selective valence state manipulation of transition metal ions in transparent materials. We observed space selective, persistent photo-oxidation of $\mathrm{Mn}^{2+}$ to $\mathrm{Mn}^{3+}$ in a silicate glass by focusing 120 fs laser pulses from a regeneratively amplified Ti sapphire laser through a microscope objective lens. Absorption and electron spin resonance spectra were measured for the glass before and after the femtosecond laser irradiation. The mechanism of the phenomenon is also discussed.

Glass composition of the $\mathrm{Mn}$ and $\mathrm{Fe}$ ions codoped silicate glass sample used in this study was $0.05 \mathrm{Fe}_{2} \mathrm{O}_{3} \cdot 0.1 \mathrm{MnO} \cdot 70 \mathrm{SiO}_{2} \cdot 10 \mathrm{CaO} \cdot 20 \mathrm{Na}_{2} \mathrm{O}(\mathrm{mol} \%)$. Regent grade $\mathrm{SiO}_{2}, \mathrm{CaCO}_{3}, \mathrm{Na}_{2} \mathrm{CO}_{3}, \mathrm{Fe}_{2} \mathrm{O}_{3}$, and $\mathrm{MnO}$ were used as starting materials. An $\sim 40 \mathrm{~g}$ batch was mixed, and placed into a platinum crucible. Melting was carried out in an electronic furnace at $1550{ }^{\circ} \mathrm{C}$ for $1 \mathrm{~h}$ under the ambient atmosphere. Glass sample was obtained by quenching the melt to room temperature. The glass sample thus obtained was transparent and colorless. The glass sample was cut, polished, and subjected to experiments. 


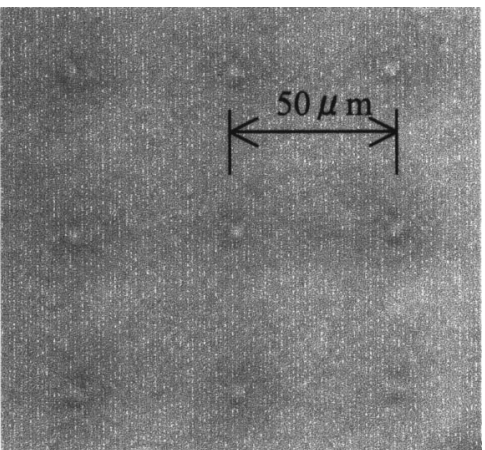

FIG. 1. Image of induced spots in the Mn and Fe ions codoped silicate glass after focused $800 \mathrm{~nm}$ femtosecond laser for $1 / 63 \mathrm{~s}$ on each spot. Distance between adjacent spots is $50 \mu \mathrm{m}$.

A regeneratively amplified 800-nm-Ti sapphire laser that emits $120 \mathrm{fs}, 1 \mathrm{kHz}$, mode-locked pulses was used for our study. The laser beam with an average power of $400 \mathrm{~mW}$ was focused by a $10 \times$ objective lens with a numerical aperture of 0.30 on the interior of the glass sample with the help of an $X Y Z$ stage. The spot size (diameter) of the laser beam was estimated to be $10 \mu \mathrm{m}$.

Absorption spectra of the glass samples were measured by a spectrophotometer (JASCO V-570). Electron spin resonance (ESR) measurements were carried out at $X$-band frequency $(9.8 \mathrm{GHz})$ by an ESR spectrophotometer (JEOLFE3X). The microwave power, time constant, modulation amplitude, and sweep time was $1 \mathrm{~mW}, 0.03 \mathrm{~s}, 1 \times 100$, and 4 $\mathrm{cm} / \mathrm{min}$, respectively. All of the experiments were carried out at room temperature.

Figure 1 shows the image of the spots after irradiation by the focused infrared femtosecond laser on each spot for 1/63 s (i.e., 16 pulses). A $4 \mu \mathrm{m}$ spot was formed in the focused area of the laser beam in the $\mathrm{Mn}$ and $\mathrm{Fe}$ ions codoped glass sample. In addition, a purple colored area with diameter of about $30 \mu \mathrm{m}$ was observed around the spot. The length of the induced structure along the axis of the laser beam was about $1.5 \mathrm{~mm}$ via the observation of optical microscope. To measure the absorption spectrum of the glass sample after the laser irradiation, we wrote a "damaged" plane of $3.0 \times 3.0$ $\mathrm{mm}^{2}$ inside the glass sample, which consisted of "damaged" lines at an interval of $10 \mu \mathrm{m}$ by scanning the laser beam at a rate of $1 \mathrm{~mm} / \mathrm{s}$. The distance of the plane from the surface of the glass sample was about $0.5 \mathrm{~mm}$.

Figure 2 shows the absorption spectra of the glass

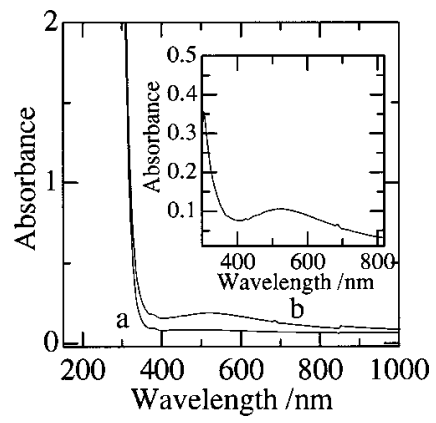

FIG. 2. Absorption spectra of the $\mathrm{Mn}$ and $\mathrm{Fe}$ ions codoped silicate glass before (a) and after (b) the femtosecond laser irradiation. The inset shows the difference spectrum between absorption of the glass sample after and

before the femtosecond laser irradiation.
Downloaded 30 May 2007 to 130.54.110.22. Redistribution subject to AlP license or copyright, see http://apl.aip.org/apl/copyright.

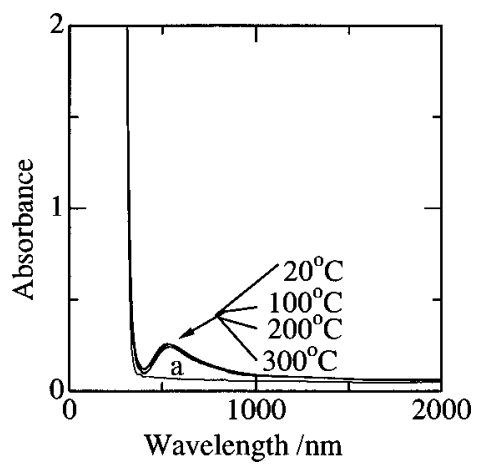

FIG. 3. Absorption spectra of the irradiated $\mathrm{Mn}$ and $\mathrm{Fe}$ ions codoped silicate glass annealed at various temperatures for $1 \mathrm{~h}$.

sample before (a) and after (b) the femtosecond laser irradiation. No apparent absorption was observed for the unirradiated glass sample in the wavelength region from 400 to 1000 $\mathrm{nm}$, while there was an apparent increase in the absorbance in the wavelength region from 300 to $1000 \mathrm{~nm}$ in the irradiated region. The inset of the Fig. 2 shows the difference absorption spectrum of the glass sample after and before the femtosecond laser irradiation. A peak ranging from 400 to $800 \mathrm{~nm}$, peaking at $520 \mathrm{~nm}$ was observed. This peak can be ascribed to the absorption of $\mathrm{Mn}^{3+}$ ions. ${ }^{15,16}$ In addition, a peak was observed at $320 \mathrm{~nm}$, which can be assigned to the absorption of hole-trapped centers as observed in the x-ray irradiated silicate glasses. ${ }^{17}$

Figure 3 shows the absorption spectra of the femtosecond laser-irradiated glass sample annealed at various temperatures for $1 \mathrm{~h}$. No apparent decrease was observed in the laser-induced absorption at temperature below $300^{\circ} \mathrm{C}$. We did not observe any variation for the absorption of the induced $\mathrm{Mn}^{3+}$ ions at room temperature even after one month. Therefore, the induced $\mathrm{Mn}^{3+}$ ions are thermally stable.

Figure 4 shows the electron spin resonance spectra of the glass sample before and after the femtosecond laser irradiation at room temperature. The spectrum of unirradiated glass exhibits a resolved hyperfine structures of six lines spread over a range of about $500 \mathrm{G}$ in width centered at $3350 \mathrm{G}$ (splitting coefficient $g \sim 2.0$ ). The spectrum showed a pattern similar to those observed for various glasses containing $\mathrm{Mn}^{2+}$ ions. ${ }^{18}$ The low resolution of the hyperfine lines is due to the dipolar broadening. In Fig. 1, no apparent absorption due to $\mathrm{Mn}^{3+}$ was observed in unirradiated glass. Therefore, most of Mn ions are present as divalent state in glass. Two

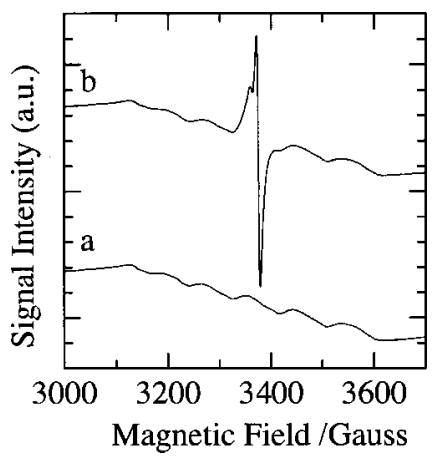

FIG. 4. Electron spin resonance spectra of the $\mathrm{Mn}$ and $\mathrm{Fe}$ ions codoped AlP license or copyright, see http://apl.aip.org/apl/copyright.jsp 


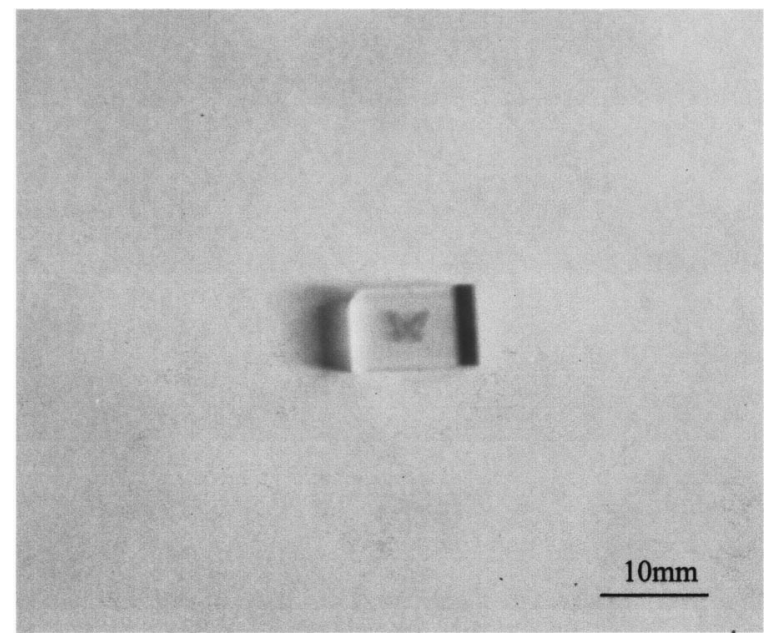

FIG. 5. Image of a butterfly in purple color written inside the glass using the femtosecond laser.

new signals at $g$ of 2.010 and 2.000 were observed in the glass sample after irradiation. The signals can be assigned to hole-trapped centers in the glass matrix. ${ }^{19}$

From the above results, a part of $\mathrm{Mn}^{2+}$ was oxidized to $\mathrm{Mn}^{3+}$ after the femtosecond laser irradiation. $\mathrm{Mn}$ and $\mathrm{Fe}$ codoped silicate glass sample has no absorption in the wavelength region near $800 \mathrm{~nm}$. Therefore, photo-oxidation of $\mathrm{Mn}^{2+}$ to $\mathrm{Mn}^{3+}$ should be a nonlinear optical process. We suggest that multiphoton absorption be one of the mechanism of the observed phenomenon. ${ }^{20}$ Free electrons are generated by the multiphoton absorption of the incident photon and consequent avalanche ionization. $\mathrm{Mn}^{2+}$ captures a hole to form $\mathrm{Mn}^{3+}$, while $\mathrm{Fe}^{3+}$ as well as active sites in glass matrix may act as electron trapping centers, resulting in the formation of $\mathrm{Mn}^{3+}$. However, the length of the induced structure $(1.5 \mathrm{~mm})$ is far longer than that of the Rayleigh length of the focused beam $(200 \mu \mathrm{m})$. Therefore, other mechanisms also should be taken into consideration. Since the power density is larger than $10^{12} \mathrm{~W} / \mathrm{cm}^{2}$, nonlinear refractive index largely contributes to the refractive index of the glass during the laser irradiation. The refractive index increases when the intensity of the laser increases and selffocusing of the laser beam occurs. On the other hand, formation of electron plasma due to electric field, causes a decrease in the real part of the refractive index and induces self-defocusing of the beam. The balance between the selffocusing due to the increase of refractive index and selfdefocusing due to the plasma formation results in a phenomenon called self-trapping or filamentation. ${ }^{21}$ In the filaments, white light supercontinuum containing Stokes and antiStokes wave is generated due to self-phase modulation. The single or two-photon absorption of short wavelength component of the white light supercontinuum causes photoionization of transition ions as well as glass matrix, leading to the formation of $\mathrm{Mn}^{3+}$. We confirmed that the length of the induced structure was directly proportional to the square root of the average power of the laser beam. If we assume that the length of the induced structure is directly proportional to the length of the filament, the result is in good agreement with the theory of Zverev et al. ${ }^{22}$ Therefore, filamentation due to the balance of self-focusing arose from an increase in refrac- tive index and self-defocusing arose from plasma formation which takes an important role in the oxidation of $\mathrm{Mn}^{2+}$ to $\mathrm{Mn}^{3+}$. The trap levels of defect centers may be deep, thus resulting in the stable $\mathrm{Mn}^{3+}$ at room temperature. The structural difference among the cross section of the induced structure may result from the high temperature and high pressure at the center part due to the strong plasma formation, and ionization of transition metal ion as well as glass matrix due to the multiphoton absorption of the incident laser and single or two photonabsorption of the white light supercontinuum.

In summary, we have observed persistent photooxidation of $\mathrm{Mn}^{2+}$ to $\mathrm{Mn}^{3+}$ in a silicate glass by a focused infrared femtosecond pulsed laser at room temperature. $\mathrm{Mn}^{2+}$ is suggested to act as hole trapping centers while $\mathrm{Fe}^{3+}$, active sites in glass matrix act as an electron trapping center. White light supercontinuum takes an important role in the formation of $\mathrm{Mn}^{3+}$. Since the focused area becomes purple after the laser irradiation, it is possible to write a three-dimensional colored image inside the transparent and colorless glass as shown in Fig. 5. Since the length of the induced structure is directly proportional to the square root of the average power of the laser beam, it is possible to control the longitudinal spreading of the oxidation area from several hundred nanometers to several millimeters by selecting the proper irradiation condition. This method should also be useful for the space-selective valence state manipulation of other transition metal ions inside transparent materials. Therefore, the present technique will be useful in the fabrication of three-dimensional colored industrial art object, optical memory, and micro-optical devices.

${ }^{1}$ E. Yablonovitch, Phys. Rev. Lett. 58, 2059 (1987).

${ }^{2}$ J. D. Joannopoulos, P. R. Villeneuve, and S. Fan, Nature (London) 386, 143 (1997).

${ }^{3}$ P. V. Braun and P. Wiltzius, Nature (London) 402, 603 (1999).

${ }^{4}$ B. H. Cumpston, S. P. Anaanthavel, S. Barlow, D. L. Dyer, J. E. Ehrlich, L. L. Erskine, A. A. Heikal, S. M. Kuebler, I.-Y. S. Lee, D. McCordMaughon, J. Qin, H. Rockel, M. Rumi, X. L. Wu, S. R. Marder, and J. W. Perry, Nature (London) 398, 51 (1999).

${ }^{5}$ M. Campbell, D. N. Sharp, M. T. Harrison, R. G. Denning, and A. J. Turberfield, Nature (London) 404, 53 (2000).

${ }^{6}$ S. Pedesen, L. Banares, and A. H. Zewail, J. Chem. Phys. 97, 8801 (1992).

${ }^{7}$ L. R. Fhundkar and A. H. Zewail, J. Chem. Phys. 92, 231 (1990).

${ }^{8}$ H. Misawa, Japanese Patent Application No. 023614 (1995); Electrics Weekly, News Page, 1995.

${ }^{9}$ K. M. Davis, K. Miura, N. Sugimoto, and K. Hirao, Opt. Lett. 21, 1729 (1996).

${ }^{10}$ K. Miura, J. Qiu, H. Inouye, T. Mitsuyu, and K. Hirao, Appl. Phys. Lett. 71, 3329 (1997).

${ }^{11}$ J. Qiu, K. Miura, H. Inouye, Y. Kondo, T. Mitsuyu, and K. Hirao, Appl. Phys. Lett. 73, 1763 (1998).

${ }^{12}$ J. Qiu, K. Miura, T. Suzuki, T. Mitsuyu, and K. Hirao, Appl. Phys. Lett. 74, 10 (1999).

${ }^{13}$ K. Miura, J. Qiu, T. Mitsuyu, and K. Hirao, Opt. Lett. 25, 408 (2000).

${ }^{14}$ J. Qiu, J. Ceram. Soc. Jpn. 109, S25 (2001).

${ }^{15}$ S. P. Singh and A. Kumar, Phys. Chem. Glasses 33, 61 (1992).

${ }^{16}$ J. Qiu, Y. Kondo, K. Miura, T. Mitsuyu, and K. Hirao, Jpn. J. Appl. Phys., Part 2 38, L649 (1999).

${ }^{17}$ Y. Yokota, Phys. Rev. 95, 1145 (1954).

${ }^{18}$ C. Sumalatha, B. Sreedhar, M. Yamazaki, and K. Kojima, Phys. Chem. Glasses 38, 206 (1997).

${ }^{19}$ A. Bishay, J. Non-Cryst. Solids 3, 54 (1970).

${ }^{20}$ B. C. Stuart, M. D. Feit, A. M. Rubenchik, B. W. Shore, and M. D. Perry, Phys. Rev. Lett. 74, 2248 (1995).

${ }^{21}$ R. R. Alfano and S. L. Shapiro, Phys. Rev. Lett. 24, 592 (1970).

${ }^{22}$ G. M. Zverev and V. A. Pashkov, Sov. Phys. JETP 30, 616 (1970). 